\title{
Analisis Bisnis Internal Dengan Metode Critical Success Factors (Csf) Dan Value Chain (Studi Kasus Pt. Farmasi X)
}

\author{
Nur Hayati ${ }^{1}$ \\ ${ }^{1}$ Fakultas Teknologi Komunikasi dan Informatika (Universitas Nasional)
}

\begin{abstract}
ABSTRAK
Sebuah keputusan yang diambil oleh seorang pemimpin sangat berpengaruh terhadap keberhasilan dari suatu organisasi untuk mencapai tujuannya, sehingga perlu suatu metode yang tepat untuk menganalisis faktor-faktor objektif yang mempengaruhi keberhasilan ataupun kegagalan dalam pencapaian tujuan tersebut. Metode Critical Success Factors (CSF) dan analisis CSF digunakan oleh PT Farmasi X untuk mengintepretasikan objek-objek secara lebih jelas untuk menentukan aktivitas yang harus dilakukan dan informasi apa saja yang dibutuhkan. CSF sendiri dapat ditentukan jika objektif atau arah dan tujuan organisasi tersebut telah diidentifikasi. Tujuan PT. Farmasi $X$ adalah masuk ke dalam 60 besar perusahaan farmasi versi IMS-ITMA. Selain CSF, analisis Value Chain juga digunakan sejalan dengan analisis CSF sehingga berguna dalam mengidentifikasi proses yang paling kritis, serta memberikan fokus pada pencapaian tujuan melalui aksi-aksi atau proses yang paling tepat untuk dilaksanakan. Aktifitas utama merupakan faktor yang paling penting dalam mewujudkan tujuan dari $P T$. Farmasi $X$, diantaranya adalah pemesanan material, forecasting penjualan, terima order dari distributor, proses produksi, pengiriman barang ke distributor, create demand, monitoring sales, evaluasi sales dan monitoring stok.
\end{abstract}

Kata kunci: Critical Success Factor (CSF), Value Chain

\begin{abstract}
A decision taken by a leader of great influence on the success of an organization to achieve its goals, so it needs an appropriate method to analyze the objective factors that influence the success or failure in achieving that goal. Method Critical Success Factors ( CSF ) and CSF analysis used by PT Pharmacy X to interpret the objects more clearly to define the activities that should be done and what information is needed. CSF can be determined if the objective or the direction and goals of the organization have been identified. nterest PT.X Pharmaceuticals is entered into 60 major pharmaceutical company IMS - ITMA version. In addition to CSF, Value Chain analysis is also used in conjunction with CSF analysis that is useful in identifying the most critical processes, and focuses on achieving goals through actions or processes that are most appropriate to be implemented. The main activity is the most important factor in realizing the goal of PT .X Pharmaceuticals, including the ordering of materials, forecasting sales, orders received from distributors, production processes, delivery of goods to the distributor, create demand, sales monitoring, evaluation and monitoring of the stock sales.
\end{abstract}

Keywords: Critical Success Factor (CSF), Value Chain 


\section{LATAR BELAKANG}

Analisis bisnis internal merupakan langkah inovatif yang mencerminkan keinginan perusahaan PT. Farmasi X yang mencerminkan keinginan perusahaan untuk melakukan perubahan untuk sebuah perbaikan terhadap kebijakan manajemen yang telah ada. Hasil analisis bisnis internal ini merupakan wahana pembaharuan terhadap kebijakan perusahaan yang selama ini telah berlangsung yang diharapkan dapat selaras dan mendukung visi dan misi perusahaan. PT. Farmasi X merupakan salah satu perusahaan yang bergerak dibidang farmasi baik ethical (prescribe only) maupun non ethical (OTC) yang berkantor pusat di kawasan industry di Jakarta. Ada beberapa yang menjadi latar belakang dilakukannya analisis internal dalam perusahaan ini, diantaranya adalah pimpinan dan staf perusahaan mengalami kesulitan dalam mempertahankan pelanggan yang berpindah ke perusahaan farmasi lain; sumber daya belum mendapatkan perhatian yang baik untuk fasilitas, pelatihan, penghargaan dan lain-lain sesuai dengan keahlian, tanggungjawab dan kierjanya; dan tujuan perusahaan untuk masuk ke dalam 60 besar perusahaan farmasi versi IMS-ITMA.

\section{METODOLOGI PENELITIAN}

\subsection{Critical Success Factors (CSF)}

CSF adalah kumpulan analisa dari banyak proses-proses penentu keberhasilan. CSF diperlukan untuk mencapai misi sebuah perusahaan. Berdasarkan hasil analisa strategi melalui SWOT, dapat ditetapkan beberapa faktor penentu kesuksesan sebuah strategi kelak setelah strategi tersebut dijalankan.

Berdasarkan artikel yang ditulis oleh Anne Parr dan Graeme Shanks di Jurnal of Information Technology (2005), dijelaskan beberapa poin CSF (Critical Success Factor) yaitu:

1. Management Support, berupa dukungan dari top management yang sangat dibutuhkan mulai dari awal project hingga project selesai.

2. Keterlibatan orang-orang yang berkompeten di bidangnya secara loyal dan menyeluruh.

3. Terdapat delegasi yang diberikan wewenang untuk memberikan keputusan, gunanya untuk mendapatkan keputusan yang lebih cepat.

4. Jadwal yang realistis dan selalu dimonitor perkembangannya.

5. Agen perubahan dimana selalu ber ' promosi ' mengenai sistem yang baru dan bertugas untuk sebagai 'pendengar' sehingga menjadi koreksi dalam implementasi.

6. Ruang lingkup yang tidak terlalu besar agar lebih efektif dan efisien.

7. Definisi tujuan dan ruang lingkup harus jelas

8. Komposisi team yang seimbang antara bisnis analis, technical expert, dan user yang ikut baik itu internal maupun yang eksternal dari suatu perusahaan

9. Komitmen untuk perubahan, ketekunan dan ketabahan dalam menghadapi masalah yang terjadi selama project.

\subsection{Value Chain}

Tidak ada teori yang sepopuler "value chain"-nya Michael Porter (Porter, 1985) di era organisasi modern saat ini, terutama yang berkaitan dengan process reengineering (pendekatan Business Process Reengineering sendiri diperkenalkan oleh Michael Hammer, namun Michael Porter memberikan kerangka metodologi untuk mengadakan proses reengineering). Porter menyarankan bahwa langkah awal yang harus dilakukan baik dalam menganalisa maupun mendesain proses bisnis yang ada di perusahaan adalah dengan membuat "value chain" (rantai nilai) dari proses-proses utama (core processes) dan aktivitas penunjangnya (supporting activities). Proses utama tidak lain adalah urutan global proses yang terjadi di perusahaan, mulai dari bahan mentah yang diperoleh dari supplier, diolah oleh perusahaan, sampai ke tangan customer atau pembeli produk maupun jasa. Gambar 1 ini merupakan "generic value chain" yang diperkenalkan Michael Porter dalam buku klasiknya "Competitive Advantage". 


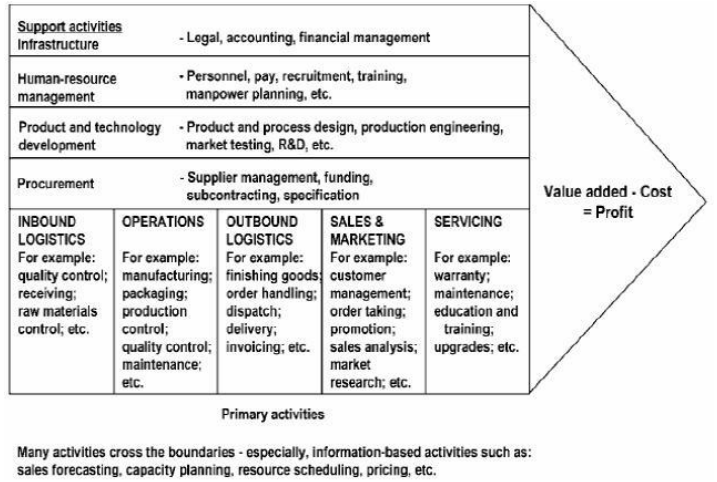

Gambar 1. Diagram Value Chain

Masalah utama dengan pendekatan ini adalah, bahwa dengan mengklasifikasikan teknologi informasi sebagai fasilitas penunjang, pelaku bisnis akan melihatnya lebih sebagai "non-value added activity" (aktivitas yang tidak memiliki nilai tambah) sehingga investasi yang diberikan akan dibatasi seminimum mungkin (karena sifatnya sebagai salah satu "cost center". Memang hal ini cukup tepat jika ingin diterapkan pada perusahaan-perusahaan manufaktur, namun kalau metode yang sama ingin diterapkan pada perusahaan yang bergerak di bidang jasa, akan berdampak cukup fatal. Mengapa? Karena dalam perusahaan jasa, yang menjadi kunci adalah kepuasan pelanggan penerima jasa yang ditawarkan perusahaan. Kepuasan pelanggan dalam hal ini tidak hanya berdasarkan kualitas pelayanan saja, namun lebih kepada fleksibilitas menerima pelayanan tersebut. Contohnya adalah seorang nasabah yang ingin dapat mentransfer uangnya ke mana saja, kapan saja, di mana saja, dan melalui cara apa saja. Tentu saja teknologi informasi di sini merupakan komponen utama dalam "core processes".

Melihat kelemahan tersebut, Porter dalam bukunya yang lain memasukkan unsur teknologi informasi ke dalam kerangka "value chain"-nya yang terlihat dalam gambar 1. Sesuai dengan teori "competitive advantage" yang ditawarkan, ada dua cara untuk melakukan persaingan dalam bisnis (Remenyi et.al., 1995):

- Product Differentiation - dengan menawarkan produk yang sama sekali baru dan sulit ditiru oleh para pesaing lain; atau

- $\quad$ Lower Price - dengan cara menjual produk sejenis dengan harga yang lebih murah.

Hal pokok yang harus diperhatikan sehubungan dengan hal ini adalah manajemen harus dapat membedakan, aplikasi teknologi informasi mana saja yang termasuk "core processes" dan yang merupakan "support activities". Sebuah konsultan internasional memberikan definisi khusus mengenai kriteria proses "value added" (yang pada dasarnya dapat digolongkan sebagai "core processes") sebagai berikut:

- Sesuatu hal yang sangat kritikal bagi bisnis perusahaan ("critical to the business"), tanpa proses yang bersangkutan, perusahaan tidak dapat berlangsung (terpaksa gulung tikar);

- Sesuatu yang secara langsung terlibat dalam proses penciptaan produk atau pelayanan yang ditawarkan perusahaan; dan

- Pelanggan bersedia "membayar" untuk keperluan proses tersebut ("customer is willing to pay for the activities"); misalnya seorang nasabah yang mau membayar ekstra Rp 50,000 per bulan untuk mendapatkan kartu ATM khusus yang dapat dipergunakan di seluruh dunia.

Investasi teknologi informasi yang layak dilakukan, adalah yang secara jelas berfungsi dalam mendukung proses "value added" di atas. Sementara untuk hal-hal yang bersifat "nonvalue added", sedapat mungkin investasi teknologi informasi harus ditekan secara minimal, karena secara langsung maupun tidak langsung akan mempengaruhi biaya pembuatan produk atau pelayan yang ditawarkan kepada pelanggan (karena biaya ini akan dikompensasikan ke dalam harga produk atau pelayanan), yang jika tidak dikontrol dengan baik, akan mengakibatkan sulitnya perusahaan berkompetisi dengan para pesaing yang menawarkan produk dan pelayanan sama dengan harga yang lebih murah. 


\section{ANALISIS DAN PEMBAHASAN}

\subsection{Analisis Bisnis Internal}

Kekuatan dan kelemahan apakah yang dimiliki perusahaan saat ini? apa sajakah yang mungkin untuk dikembangkan pada masa yang akan datang? Pertanyaan ini baru dapat dijawab dengan baik setelah melakukan analisis terhadap lingkungan internal perusahaan. Jadi analisis internal merupakan suatu proses untuk menemukan aspek-aspek internal/variabel internal perusahaan yang diperlukan dalam menghadapi lingkungan eksternalnya dan mengevaluasinya apakah suatu perusahaan berada dalam posisi yang kuat atau lemah

\subsubsection{Analisis $C S F$}

CSF sangat diperlukan untuk mencapai misi perusahaan. Hasil analisis ini nantinya dapat digunakan untuk menentukan strategi perusahaan ke depannya. Berikut merupakan CSF dari beberapa sasaran yang ada:

1. PT. Farmasi X kurang dikenal dikalangan Dokter, Rumah Sakit dan Apotik.

2. Masih menggunakan konsep supermarket

3. Memiliki produk unggulan yang tidak dimiliki oleh farmasi lain

4. Memiliki 27 cabang distribusi

5. Bahan baku impor, sehingga harga bahan baku tergantung kurs mata uang dollar.

6. Memiliki laboratorium pengujian obat

7. Good financial support

8. Sistem keuangan dan marketing yang belum terintegrasi.

9. Pengecekan secara manual untuk setiap transaksi keuangan.

10. Jumlah staf Marketing 203 orang

11. Strata pendidikan karyawan terdiri dari S-2, S-1, D-3 dan SMA

12. Mempunyai marketing support

\subsubsection{Value Chain}

Prinsip disagregasi perusahaan juga digunakan pada pendekatan ini, sama seperti pendekatan Competitive Advantage. Pendekatan ini digagas oleh Michel Porter pada tahun 1980an atau lebih tua dibanding pendekatan keunggulan bersaing.

Pada pendekatan ini untuk memperoleh tingkat margin diperlukan aktifitas bisnis yang dikelompokan atas :

1. Aktifitas utama

2. Aktifitas penunjang

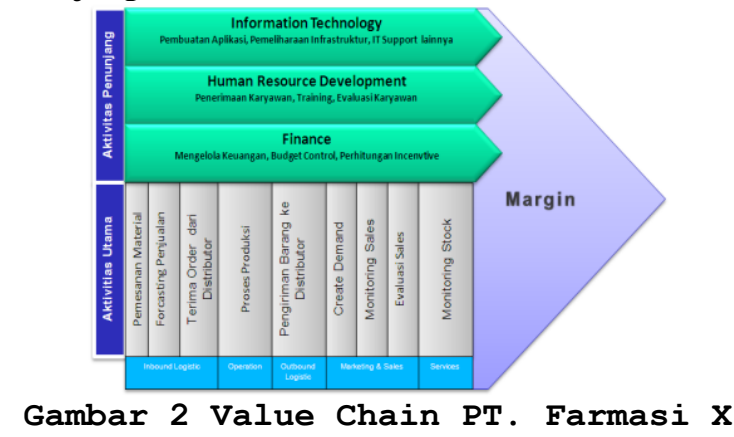

Aktifitas-aktifitas utama perlu untuk diperhatikan agar bekerja dengan baik serta dukungan oleh aktifitas penunjang. Dengan memperhatikan setiap aktifitas dan keketerkaitan antar masing-masing, maka diharapkan perusahaan dapat meningkatkan kinerja masing-masing aktifitas dan menciptakan sinergi agar terciptanya keunggulan perusahaan. 


\section{KESIMPULAN}

Berdasarkan hasil yang diperoleh dari pembahasan, dapat diambil kesimpulan:

1. Hasil analisis menggunakan metode CSF menunjukkan bahwa sistem marketing pada PT. Farmasi X masing harus dikembangkan sehingga produk dari PT. Farmasi X terkenal dikalangan Dokter, Rumah Sakit dan Apotik. Selain itu, sistem informasi harus terintegrasi antara divisi.

2. Hasil analisis Value Chain menunjukkan bahwa aktifitas utama merupakan faktor yang paling penting dalam mewujudkan tujuan dari PT. Farmasi X, diantaranya adalah pemesanan material, forecasting penjualan, terima order dari distributor, proses produksi, pengiriman barang ke distributor, create demand, monitoring sales, evaluasi sales dan monitoring stok.

\section{DAFTAR RUJUKAN}

[1] Blue Print PT. Farmasi X

[2] Widarsono, Agus. 2009. Strategic Value Chain Analysis: Suatu pendekatan Manajemen Biaya

[ 3 ] Sujana, I Ketut. 2006. Aplikasi Activity Based Costing (ABC) Dalam Analisis Value Chain Dan Keunggulan Kompetitif. Buletin Studi Ekonomi, Volume 11 Nomor 3

[ 4 ] Layton Caesar, Januar Rustandie. 2007. Gambaran Rantai Nilai Komponen Otomotif Justifikasi Pasar Dan Strategi Peningkatan Pasar Komponen Dalam Negeri

[ 5 ] Pearce II, John. A and Richard B. Robinson. 2009. Strategic Management Formulation, Implementation and Control. Mc Graw-Hill International Edition. USA 